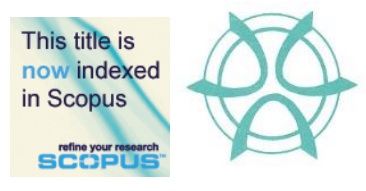

PLANNING MALAYSIA:

Journal of the Malaysian Institute of Planners

VOLUME 17 ISSUE 2 (2019), Page 92 - 100

\title{
VEHICLE - PEDESTRIAN CONFLICT: A CASE STUDY IN UNIVERSITI PUTRA MALAYSIA
}

\author{
Noorain Mohd Isa ${ }^{1}$, Ahmad Zaharin Aris ${ }^{2}$, Zakiah Ponrahono ${ }^{3}, \&$ Rosta Harun ${ }^{4}$ \\ ${ }^{1,2,3,4}$ Faculty of Environmental Studies \\ UNIVERSITI PUTRA MALAYSIA
}

\begin{abstract}
Vehicle-pedestrian conflict is a commonly unsafe event that occurs in both urban and rural areas, especially in developing countries. It is still an open research topic, mostly in traffic safety and urban planning, which is utilised for evaluating the behaviours of vehicles and pedestrians at a non-signalised marked walkway. Three stations were selected based on higher daily activities to calculate the regularity of pedestrian movement. A manual calculation method was applied, and the calculation was done only during the daytime. Three different teams were formed to obtain the measurements at the three different sampling points simultaneously. A present study on preliminary vehicle-pedestrian conflict reveals the frequency of pedestrians in a concentrated area and its Level of Service (LOS) in Universiti Putra Malaysia (UPM) Serdang. The findings show that rush hour occurs during the mid-day in weekday, when students have finished their classes and adults have gone out for other businesses.
\end{abstract}

Keywords: campus, pedestrian, non-motorised vehicle, shared pathway 
PLANNING MALAYSIA

Journal of the Malaysia Institute of Planners (2019)

\section{INTRODUCTION}

Urban areas, especially in developing countries, commonly have mixed traffic flows (Ni, Wang, Sun, \& Li, 2016). In this approach of mixed traffic, motor vehicles, non-motorised vehicles (bicycles) and pedestrians share the same space (roads and intersections), which in turn triggers conflicts (Almodfer, Xiong, Fang, Kong, \& Zheng, 2016). These vehicle-vehicle conflicts, bicycle-vehicle conflicts, and pedestrian-vehicle conflicts occur frequently, with vehiclepedestrian conflicts being the most concerning issue.

The behaviour of pedestrians and drivers can become a great influence, which depends on many uncertain factors (Suzuki \& Ito, 2017). For example, pedestrians and cyclists may step out onto the road without warning and sometimes are unaware or being less alert around traffic, which present risk of collision with vehicles. Besides that, the millennial generation tends to obsess over their smart phones, texting or talking and being seemingly ignorant of their surroundings (Cloutier et. al., 2017). On the other hand, drivers of motorised vehicles could also be using their smart phones while driving, compromising their attention to the road. Policy and decision makers around the world have typically prioritised the safety of pedestrians (Iryo-Asano \& Alhajyaseen, 2017). However, these intentions get less attention due to increasing vehicle congestion in urban areas. Additionally, pedestrian areas have been minimised to allow for better road openings.

Pedestrians are vulnerable road users because of their unprotected safety on the road (Zheng, Chase, Elefteriadou, Schroeder, \& Sisiopiku, 2015). In Malaysia, more than 6,000 cases involving pedestrian injuries and fatalities on the road are reported annually. Meanwhile, pedestrian fatalities are averages at 500 deaths each year (Mohd Syazwan, Baba, Nur Zarifah, Aqbal Hafeez, \& Noor Faradila, 2017). Most injuries involve the elderly (60 years above), and $>60 \%$ of these accidents occurred on straight roads. The fatality statistics of pedestrians has been showing a continued increase from $24.4 \%$ in 2006 to $44.2 \%$ in 2013, and thus needs to be attended to. Table 1 shows the fatalities involving pedestrians in Southeast Asian countries.

Universiti Putra Malaysia (UPM) has set a new record when it was listed as the world's top $17^{\text {th }}$ university in the UI-Greenmetric World University Ranking based on its rigorous efforts to promote campus sustainability and effective environmental management. In year 2013, UPM established a cycling space for the students to cycle in the campus as part of its green campus initiative. This benefits the students by improving air quality, minimising pollution and road damage, and promotes healthy living. This could also reduce the frequencies of bus service within the campus. These bicycle lanes have been built on the existing roads, which are also being used by other vehicles. The bicycle lanes themselves are shared with pedestrian. 
Noorain Mohd Isa, Ahmad Zaharin Aris, Zakiah Ponrahono, \& Rosta Harun

Vehicle-Pedestrian Conflict: A Case Study in Universiti Putra Malaysia

Table 1 Pedestrian causalities in Southeast Asian countries in 2015

\begin{tabular}{lcc}
\hline $\begin{array}{l}\text { Southeast Asian } \\
\text { Country }\end{array}$ & $\begin{array}{c}\text { Reported Road traffic } \\
\text { Fatalities (Count) }\end{array}$ & $\begin{array}{c}\text { Death by Pedestrian } \\
\text { Category (Percentage) }\end{array}$ \\
\hline Laos DPR & 910 & $10 \%$ \\
\hline Malaysia & 6,915 & $7 \%$ \\
\hline Myanmar & 3,612 & $26 \%$ \\
\hline Philippines & 1,513 & $19 \%$ \\
\hline Singapore & 159 & $27 \%$ \\
\hline Thailand & 14,059 & $8 \%$ \\
\hline Vietnam & 9,156 & - \\
\hline Cambodia & 1,950 & $13 \%$ \\
\hline Brunei & 54 & $9.20 \%$ \\
\hline Indonesia & 26,460 & $21 \%$ \\
\hline Timor-Leste & 74 & Source: Modified from Mohd Syazwan et al. (2017)
\end{tabular}

UPM has made significant improvements, particularly in the sectors of transport and infrastructure, such as the size of available green space, the use of efficient energy-saving facilities and bicycles within the campus area. However, in terms of pedestrian and cyclist space there are still some issues regarding both groups, especially with regards to the shared pathway with motorised vehicles. Vehicle-pedestrian/cyclist interactions are commonly inter-related with traffic safety. In addition, the shared pathways between both parties could increase interaction conflict. Pedestrian and cyclist safety is also an important matter, especially at night. Low light conditions add difficulties for the visibility of both vehicles and pedestrians/cyclists (King, Wood, Lacherez, \& Marszalek, 2012). Neglecting the necessary dimensions could cause injuries to the pedestrian/cyclist. Hence, important measures should be in place to ensure pedestrian/cyclist safety on walkways and cycling lanes.

This paper intends to contribute to the existing body of knowledge in terms of, firstly, quantifying pedestrian frequency in the study are, and secondly, evaluating the Level of Service (LOS) as well as exploring the factor of pedestrian-vehicle conflicts.

\section{RESEARCH BACKGROUND}

This study is based on the observational method (counted measurement) and data was collected using the manual count method. The study sites chosen are situated at three (3) intersections in the north campus of Universiti Putra Malaysia; namely V1 - Junction at Persiaran Tulang Daing (CIMB Bank), V2 - Junction at Persiaran Tulang Daing (Faculty of Forestry) and V3 - Junction at Persiaran Asam Jawa (Faculty of Educational Studies) (Figure 1). These sites were selected as they are considered high density areas with a high capacity of pedestrian activities. 


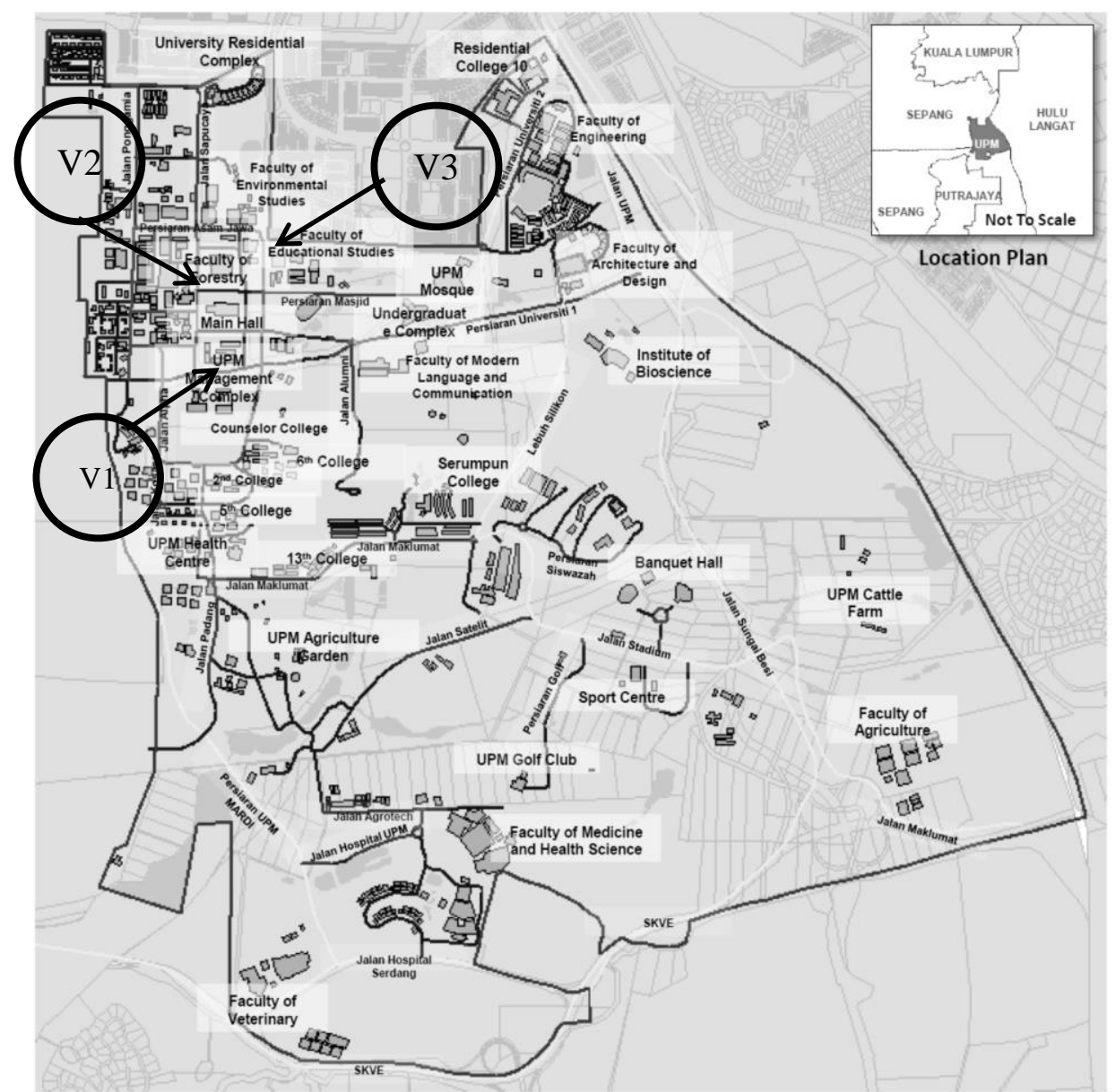

Figure 1 The study area is located at the north campus in Universiti Putra Malaysia.

The pedestrian volume counter was used to determine the volume of pedestrians using a walkway or crossing a street either at a signalised or nonsignalised intersection. Normally, pedestrian volume counts at each walkway should be made during the same period as the vehicle volume count. Tallies should also be made during the same periods as the vehicle volume count.

The pedestrian data collection processes started with pre-site survey preparation, where all the equipment, such as manual counter, safety jacket and tally sheet, was prepared. Then, sampling points were selected by selecting locations with a clear view of the pedestrian walk, and was safe and away from danger. Next, by using the tally sheet, each data collected was filled in and merged with other data at the end of the sampling day. Data collection in every area was carried out by an assigned team member at a pre-determined site. The observations were conducted during the day of three (3) days, day 1 (Thursday), 
Noorain Mohd Isa, Ahmad Zaharin Aris, Zakiah Ponrahono, \& Rosta Harun

Vehicle - Pedestrian Conflict: A Case Study in Universiti Putra Malaysia

day 2 (Friday) and day 3 (Saturday) - from 0800 to 1900 - at intervals of 15 minutes. Once a complete set of data was obtained, analyses were carried out using the Statistical Package for Social Science and the results were evaluated to identify the Level of Service (LOS).

\section{RESULTS AND DISCUSSION}

\section{Pedestrian volume}

Each sampling point consists of three (3) different junctions, namely D1, D2 and D3 (Figure 2). The pedestrian frequency analysis explains the total number of pedestrians at a designated time. The results of three (3) days sampling are summarized in Figure 2. Station V1 has the higher volume of pedestrians in day 1 which occurred at mid-day with a total of 758 pedestrians while total pedestrians for a day are 2904. This number is expected to be high as people were going out for lunch and other businesses as this area is where the bank, food court and the road to students' residences are located. Meanwhile, station V2 has a different pattern as this area consists of faculty buildings and the main library across the road. Usually, students would complete their classes and walk to the library or the bus stop at mid-day and during the evening. The average total volume of pedestrians over the course of one day was 664 and the highest volumes of pedestrians were recorded on day 2 with 1071. At station V3, pedestrians usually walk by to reach the Faculty of Education and Lecture Hall beside the parking lot. Only certain students involved in classes in the Lecture Hall would walk to this area. Lecture times are usually packed from morning to afternoon and reduced in the evening, with a total average of pedestrians of 659, 246 and 54 during 3 days sampling periods respectively. The summary of pedestrian volume is as shown in Figure 2.

The Highway Capacity Manual (HCM) uses LOS as a qualitative measure to describe operational conditions of pedestrian circulation. The HCM's method for analysing pedestrian LOS is based on the measurement of pedestrian flow rate and sidewalk space. For this survey, pedestrian queuing LOS was used as a standard to measure pedestrian LOS because the flow pattern for pedestrian is quite similar to that of queuing. Table 2 below shows the LOS criteria for pedestrian.

The LOS output shows that the LOS value varies in spatial and temporal scale. Station V1 indicate of $88 \%$ of LOS output is F (day 1), which is described as "standing, where virtually all persons are standing in direct physical contact with others and no movement is possible in the queue". This is because at this moment, most pedestrians use this route during the given time and the space along the pedestrian route is only $3.1 \mathrm{~m}$ wide. In day 2 , station $\mathrm{V} 1$ experienced moderate LOS with $29 \%$ of A and D criteria and $100 \%$ of A criterion in day 3. Meanwhile, station V2 was observed with steady LOS in day 1 where the LOS having $38 \%$ 
of D and F criteria. Comparatively, day 2 and day 3 having highest LOS of F and A criteria with $54 \%$ and $83 \%$ respectively.

For station V3, the highest LOS for day 1 and 3 are A criterion with $42 \%$ and $100 \%$ respectively showing the description of "Standing and free circulation through the queuing area is possible without disturbing others within the queue". Day 2 for station V3 showing an average condition of LOS with $29 \%$ of criteria $\mathrm{A}$ and $\mathrm{D}$ for the reason of different time period. Furthermore, Day 2 of the survey was conducted on a Friday, where most of the male students are performing the Friday prayers.

Day 3 of sampling campaign shows low pattern of movement in each station. This is because most of undergraduate student stayed in the residential area but only certain students that enrolled in credited cocurricular activities or postgraduate students having their classes in the main campus are using the pedestrian walkway.
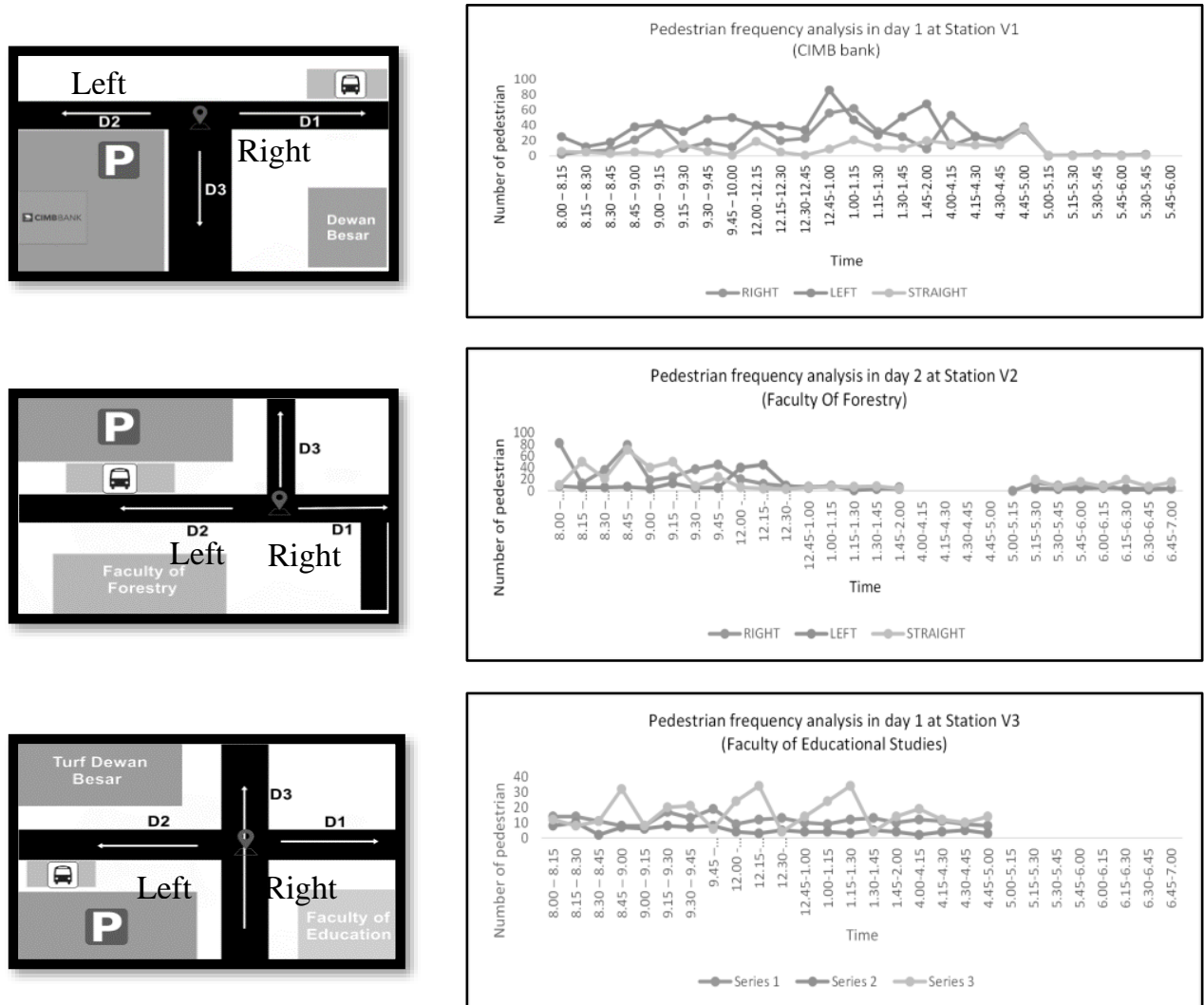

Figure 2 Summary of highest pedestrian volume (left) \& summary of pedestrian volume (right) 
Noorain Mohd Isa, Ahmad Zaharin Aris, Zakiah Ponrahono, \& Rosta Harun

Vehicle-Pedestrian Conflict: A Case Study in Universiti Putra Malaysia

Table 2 Level of service criteria for pedestrian

\begin{tabular}{|c|c|c|c|c|c|c|c|c|c|c|c|c|}
\hline \multirow[b]{3}{*}{ Station } & \multicolumn{4}{|c|}{ Day 1 (Thurs) } & \multicolumn{4}{|c|}{ Day 2 (Fri) } & \multicolumn{4}{|c|}{ Day 3 (Sat) } \\
\hline & \multicolumn{12}{|c|}{ Time } \\
\hline & $\begin{array}{c}0800 \\
- \\
1000\end{array}$ & $\begin{array}{c}1200 \\
- \\
1400\end{array}$ & $\begin{array}{l}1600 \\
- \\
1800\end{array}$ & $\begin{array}{c}\text { Total } \\
\text { pedestrian } \\
/ \mathrm{hr}\end{array}$ & $\begin{array}{c}0800 \\
- \\
1000\end{array}$ & $\begin{array}{c}1200 \\
- \\
1400\end{array}$ & $\begin{array}{c}1600 \\
- \\
1800\end{array}$ & $\begin{array}{c}\text { Total } \\
\text { pedestrian } \\
/ \mathrm{hr}\end{array}$ & $\begin{array}{c}0800 \\
- \\
1000\end{array}$ & $\begin{array}{l}1200 \\
- \\
1400\end{array}$ & $\begin{array}{c}1600 \\
- \\
1800\end{array}$ & $\begin{array}{c}\text { Total } \\
\text { pedestrian } \\
/ \mathrm{hr}\end{array}$ \\
\hline V1 & 427 & 755 & 305 & 1487 & 356 & 128 & 105 & 589 & 39 & 47 & 35 & 121 \\
\hline V2 & 235 & 282 & 241 & 758 & 662 & 231 & 178 & 1071 & 69 & 53 & 41 & 163 \\
\hline V3 & 278 & 272 & 109 & 659 & 29 & 82 & 135 & 246 & 18 & 18 & 18 & 54 \\
\hline \multicolumn{4}{|c|}{ Total } & 2904 & & & & 1906 & & & & 338 \\
\hline LOS & & $\begin{array}{l}\text { verag } \\
\text { Space } \\
\left.\mathbf{m}^{2} / \mathrm{p}\right)\end{array}$ & & \multicolumn{9}{|c|}{ Description } \\
\hline A & \multicolumn{3}{|c|}{$>1.2$} & \multicolumn{9}{|c|}{$\begin{array}{l}\text { Standing and free circulation through the queuing area is possible } \\
\text { without disturbing others within the queue. }\end{array}$} \\
\hline B & \multicolumn{3}{|c|}{$>0.9-1.2$} & \multicolumn{9}{|c|}{$\begin{array}{l}\text { Standing and partially restricted circulation to avoid disturbing } \\
\text { others in the queue is possible. }\end{array}$} \\
\hline C & \multicolumn{3}{|c|}{$>0.6-0.9$} & \multicolumn{9}{|c|}{$\begin{array}{l}\text { Standing and restricted circulation through the queuing area by } \\
\text { disturbing others in the queue is possible. }\end{array}$} \\
\hline D & \multicolumn{3}{|c|}{$>0.3-0.6$} & \multicolumn{9}{|c|}{$\begin{array}{l}\text { Standing without touching is possible; circulation is severely } \\
\text { restricted within the queue and forward movement is only } \\
\text { possible as a group. }\end{array}$} \\
\hline $\mathbf{E}$ & \multicolumn{3}{|c|}{$>0.2-0.3$} & \multicolumn{9}{|c|}{$\begin{array}{l}\text { Standing in physical contact with others is unavoidable; } \\
\text { circulation in the queue is not possible; queuing can only be } \\
\text { sustained for a short period without serious discomfort. }\end{array}$} \\
\hline $\mathbf{F}$ & \multicolumn{3}{|c|}{$\leq 0.2$} & \multicolumn{9}{|c|}{$\begin{array}{l}\text { Standing virtually all persons within the standing in direct } \\
\text { physical contact with others and no movement is possible in the } \\
\text { queue. }\end{array}$} \\
\hline
\end{tabular}

Table 3 Summary of Level of Service (LOS) in 3 days for each station

\begin{tabular}{|c|c|c|c|c|c|}
\hline Station & Day & Thurs) & Da & (Firi) & Day 3 (Sat) \\
\hline & $\mathrm{D}=4 \%$ & & $A=29 \%$ & $\mathrm{D}=29 \%$ & $\mathrm{~A}=100 \%$ \\
\hline V1 & $\mathrm{E}=8 \%$ & & $\mathrm{~B}=4 \%$ & $\mathrm{E}=10 \%$ & \\
\hline & $\mathrm{F}=88 \%$ & & $C=14 \%$ & $\mathrm{~F}=14 \%$ & \\
\hline & $\mathrm{A}=4 \%$ & $\mathrm{E}=16 \%$ & $\mathrm{C}=18 \%$ & $\mathrm{~F}=54 \%$ & $\mathrm{~A}=83 \%$ \\
\hline $\mathbf{V 2}$ & $\mathrm{C}=4 \%$ & $\mathrm{~F}=38 \%$ & $\mathrm{D}=18 \%$ & & $\mathrm{~B}=13 \%$ \\
\hline & $\mathrm{D}=38 \%$ & & $\mathrm{E}=10 \%$ & & $\mathrm{D}=4 \%$ \\
\hline & $A=42 \%$ & $\mathrm{D}=13 \%$ & $\mathrm{~A}=29 \%$ & $\mathrm{D}=29 \%$ & $A=100 \%$ \\
\hline V3 & $\mathrm{B}=4 \%$ & $\mathrm{E}=25 \%$ & $\mathrm{~B}=4 \%$ & $\mathrm{E}=10 \%$ & \\
\hline & $\mathrm{C}=8 \%$ & $\mathrm{~F}=8 \%$ & $C=14 \%$ & $\mathrm{~F}=14 \%$ & \\
\hline
\end{tabular}


PLANNING MALAYSIA

Journal of the Malaysia Institute of Planners (2019)

\section{CONCLUSION}

In this study, by using the data collected from three stations, the pedestrian volume pattern was generated. The distribution of pedestrian varies between spatial and temporal measurement. The highest contribution of pedestrian volume is during weekday where most of the students will be around the main campus for lecture time. It also indicates that most of the students will be concentrated in an area of lecture hall and library. From the findings, the Level of Services (LOS) were measured. The LOS criteria also strongly depend on the spatial and temporal distribution as for present study, most of the station experience criterion $\mathrm{F}$ during weekday which explains issues on crowd and congestion while criterion A during weekend.

Based on the output, the preliminary data can be used to explore diverse and complex pedestrian-vehicle interactions and pair these with sufficient considerations when evaluating pedestrian safety. In the future, the development of walkway designs and the addition of safety and visibility features can reduce the probability of interactions between crossing pedestrians and vehicles. Awareness of both drivers and pedestrians to respect each other's space requires an understanding of where, between whom, and under what circumstances interactions can occur. Such an approach can also help identify which engineering, urban design and enforcement programs are needed to ensure safe pedestrian crossings for all ages.

\section{ACKNOWLEDGEMENTS}

This research was fully supported by the UPM Putra Grant - Current Issue 9300437 managed by UPM RMC

\section{REFERENCES}

Almodfer, R., Xiong, S., Fang, Z., Kong, X., \& Zheng, S. (2016). Quantitative analysis of lane-based pedestrian-vehicle conflict at a non-signalized marked crosswalk. Transportation Research Part F: Traffic Psychology and Behaviour, 42, 468-478.

Cloutier, M.-S., Lachapelle, U., Amours-Ouellet, A.-A. d., Bergeron, J., Lord, S., \& Torres, J. (2017). "Outta my way!" Individual and environmental correlates of interactions between pedestrians and vehicles during street crossings. Accident Analysis \& Prevention, 104, 36-45.

Iryo-Asano, M., \& Alhajyaseen, W. K. M. (2017). Modeling pedestrian crossing speed profiles considering speed change behavior for the safety assessment of signalized intersections. Accident Analysis \& Prevention, 108, 332-342.

King, M. J., Wood, J. M., Lacherez, P. F., \& Marszalek, R. P. (2012) Optimism about safety and group-serving interpretations of safety among pedestrians and cyclists in relation to road use in general and under low light conditions. Accident Analysis \& Prevention, 44(1), 154-159.

Mohd Syazwan, S., Baba, M. D., Nur Zarifah, H., Aqbal Hafeez, A., \& Noor Faradila, P. (2016). Prevalence of distracted pedestrians while crossing: A study of Malaysia's situation. MATEC Web of Conferences, 9001031. 
Noorain Mohd Isa, Ahmad Zaharin Aris, Zakiah Ponrahono, \& Rosta Harun

Vehicle-Pedestrian Conflict: A Case Study in Universiti Putra Malaysia

Ni, Y., Wang, M., Sun, J., \& Li, K. (2016). Evaluation of pedestrian safety at intersections: A theoretical framework based on pedestrian-vehicle interaction patterns. Accident Analysis \& Prevention, 96, 118-129.

Suzuki, K. \& Ito, H. (2017). Empirical analysis on risky behaviors and pedestrian-vehicle conflicts at large-size signalized intersections. Transportation Research Procedia, $25,2139-2152$.

Wazana, A. (1997). Are there injury-prone children? A critical review of the literature. The Canadian Journal of Psychiatry, 42(6), 602-610.

Zheng, Y., Chase, T., Elefteriadou, L., Schroeder, B., \& Sisiopiku, V. P. (2015). Modeling vehicle-pedestrian interactions outside of crosswalks. Simulation Modelling Practice and Theory, 59, 89-110

Received: $12^{\text {th }}$ January 2019. Accepted: $2^{\text {nd }}$ August 2019 